\title{
Da Santa Ceia às Bodas de Caná \\ na Bahia: estudo da iconografia \\ musical nos azulejos da lgreja \\ Basílica de N. S. do Bonfim
}

Pablo Sotuyo Blanco*

Universidade Federal da Bahia

\section{Resumo:}

O presente artigo aborda o processo e os eventuais obstáculos inerentes à catalogação de Iconografia musical no contexto do RIdIM-Brasil, projeto de indexação, catalogação, pesquisa e divulgação do patrimônio iconográfico musical brasileiro. Desde a sua fundação em fevereiro de 2008, iniciou as suas atividades em Salvador, Bahia. O patrimônio iconográfico musical inclui toda e qualquer representação imagética (em duas ou três dimensōes) relativa à música, incluindo cenas. personagens, instrumentos, coreografias, performance, notação musical e até cenogragias e vestuário, dentre as mais relevantes. Exemplifica-se aqui o referido processo de catalogação com um dos 28 painéis de azulejos da Igreja Basílica de Nosso Senhor do Bonfim, em Salvador (Bahia), em virtude de ser o religioso um dos vetores sócio-culturais mais importantes da cidade, do município e do Estado.

Palavras-chave: iconografia musical; Igreja do Bonfim; Bahia; RIdIM; Veronese

* Pablo Sotuyo é formado em Composição musical pela Escola Universitária de Música (Montevidéu, Uruguai) em 1997 e Doutor em Música pelo PPGMUS-UFBA (2003), Atualmente é Professor Adjunto I do Dpto. CLEM (Composição, Literatura e Estruturação Musical) da Escola de Música da Universidade Federal da Bahia (EMUS-UFBA), lecionando tanto na graduação quanto na pós-graduação dessa unidade. Coordenador da vertente musicológica histórica do Núcleo de Estudos Musicais (NEMUS), é também representante para o Nordeste dó projeto RISM-Brasil e presidente da Comissão Mista do projeto RIdIMBrasil (período 2008-2010). 


\section{Introdução}

O Repertório Internacional de Iconografia Musical no Brasil (RIdIM-Brasil) é um projeto de indexação, catalogação, pesquisa e divulgação do patrimônio iconográfico musical brasileiro de alcance nacional. Vinculado ao Répertoire International d'Iconographie Musicale (RIdIM) desde a sua fundação em fevereiro de 2008, iniciou as suas atividades em Salvador, Bahia, onde tem sede a sua primeira Comissão Mista, integrada por representantes de diversas instituições de ensino, pesquisa e patrimônio iconográfico musical como a UFBA, as Diretorias de Bibliotecas, de Arquivos e de Museus do Estado, além de outras instituições vinculadas de uma ou outra forma ao patrimônio iconográfico musical de interesse, como instituições religiosas de diversas origens e credos.

O patrimônio iconográfico musical inclui toda e qualquer representação imagética (em duas ou três dimensões) relativa à música, incluindo cenas, personagens, instrumentos, coreografias, performance, notação musical e até cenografias e vestuário, dentre as mais relevantes.

Destarte, o RIdIM-Brasil congrega pesquisadores, profissionais, técnicos e representantes indicados pelas instituições de apoio participantes para providenciar a identificação, catalogação e disponibilização das informações relativas à iconografia musical, ao mesmo tempo que promove, desenvolve e divulga pesquisas no mesmo campo de estudo (iconografia musical). Nesse sentido, o RIdIM-Brasil lida com métodos e princípios de catalogação de obras e documentos de interesse iconográfico musical e busca disseminar a informação relativa às suas diversas atividades. ${ }^{1}$

No início das atividades do referido projeto interinstitucional, dentre as diversas possibilidades de trabalho (arquivos, bibliotecas, museus, coleções particulares, etc.) para darmos início ao processo de catalogação da iconografia musical, nos concentramos no âmbito religioso, no município de Salvador, em

\footnotetext{
${ }^{1}$ Para maiores informações e contatos; o leitor pode visitar a página oficial do RIdıM-Brasil em: <http://www.ridim-br.mus.ufba.br>.
} 
virtude de ser o religioso um dos vetores sócio-culturais mais importantes da cidade, do município e do Estado.

A partir do mapeamento inicial dos templos cristãos nesta cidade, e identificados dentre eles os católicos (cujo interesse histórico e cultural é notadamente maior), decidimos então realizar o levantamento do patrimônio iconográfico musical na Basílica do Nosso Senhor do Bonfim em função do seu valor histórico iconográfico. De toda a iconografia musical localizada nessa Basílica, chamou a nossa atenção um painel historiado de azulejos, em particular. De fato, este é o único painel de azulejos (dentre os 28 painéis de azulejos sem título e sem autoria visível que decoram as suas galerias laterais) claramente relacionado ao projeto iconográfico musical RIdIM-Brasil por incluir um trio de instrumentistas na cena (Fig. 1).

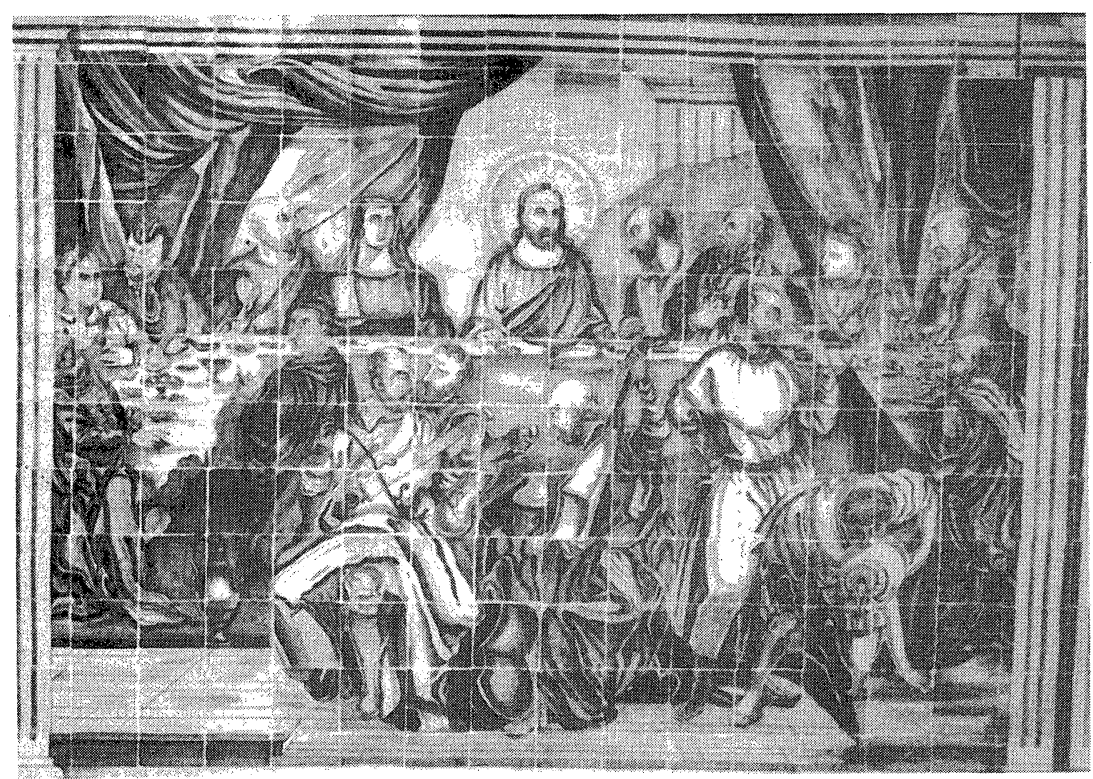

Figura 1 Painel historiado de azulejos da Igreja de N. S. do Bonfim (vista completa - 1,8 x 2,4 m) 
Segundo surge da observação preliminar, a cena representa uma refeição (não se pode afirmar se diurna ou noturna) com Jesus Cristo (destacado com o tradicional halo ao redor da cabeça) sentado ao centro de uma mesa em formato de $U$, acompanhado por outras 17 pessoas, incluindo aparentemente seus discípulos e duas mulheres: uma possível Maria [Madalena?] à esquerda de Jesus e uma outra mulher de maior idade no extremo esquerdo da imagem, e que bem poderia ser Maria (mãe de Jesus) por trás da figura semi-oculta de um dos comensais. Em primeiro plano se destaca um trio de músicos tocando violas da gamba, conjunto instrumental que os azulejos aparentemente fora de lugar não impedem o seu reconhecimento (Fig. 2).

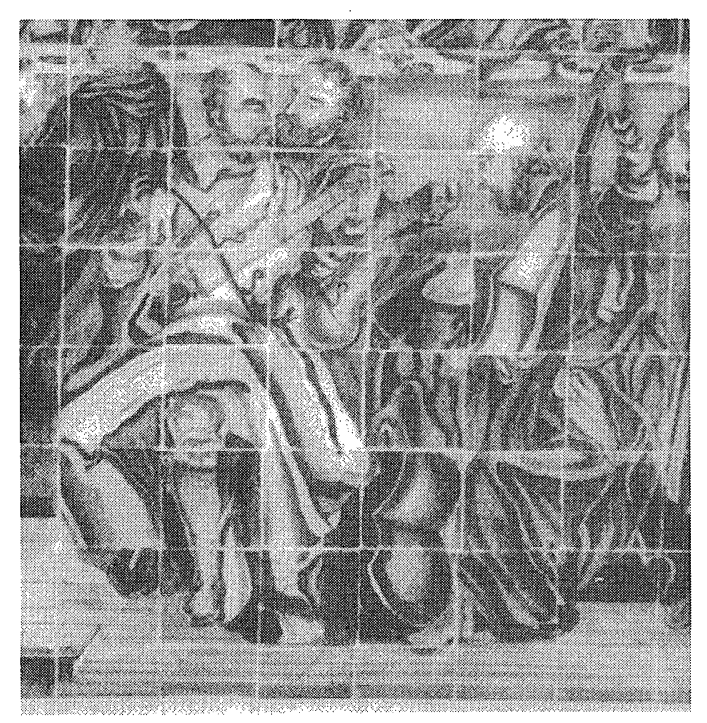

Figura 2 Painel historiado de azulejos da Igreja do Bonfim (detalhe do trio de violas)

Um observador qualquer poderia cogitar a idéia de ter localizado uma representação da última ceia incluindo dentre os diversos comensais (além do trio de músicos), uma provável Maria [Madalena?] imediatamente à esquerda de Jesus (Fig. 3). Mas a composição da cena, considerando a atitude dos outros comensais representados, não parece condizer com a importância nem 
com a seriedade daquele momento bíblico. Poucos dentre eles pareceriam estar preocupados com a presença de Jesus Cristo, sendo representados com atitudes bem mais relaxadas do que seria de se esperar naquela ocasião.

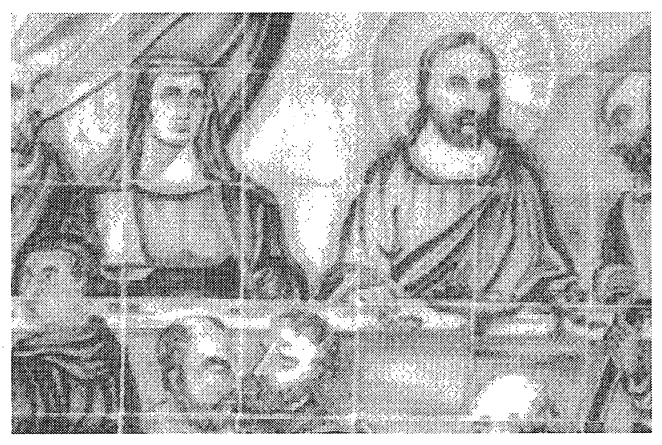

Figura 3 Azulejo historiado da Igreja do Bonfim (detalhe de Jesus Cristo e Maria [Madalena?])

Tendo em vista o processo de catalogação descritiva desse painel de azulejos na ficha de catalogação do RIdIM, o seu preenchimento inicial a partir da informação primária disponível (aquela surgida da representação iconográfica musical) ainda deixou muitas dúvidas, como se observa no

72 Quadro 1 (ver Quadro 1 na próxima página).

Para responder a tais questões presentes neste Quadro, se requer naturalmente um conhecimento mais profundo do contexto em que a obra está localizada, do seu histórico, do tema bíblico representado e dos protagonistas envolvidos, como artistas, vendedores etc. $\mathrm{Na}$ busca de tais informações, começaremos com o estudo do contexto em que se localiza este painel, isto é, o conjunto dos painéis historiados de azulejos da Basílica de N. S. do Bonfim. 
Quadro 1 Preenchimento primário da Ficha de catalogação do projeto RIdIM-Brasil (frente) ${ }^{2}$

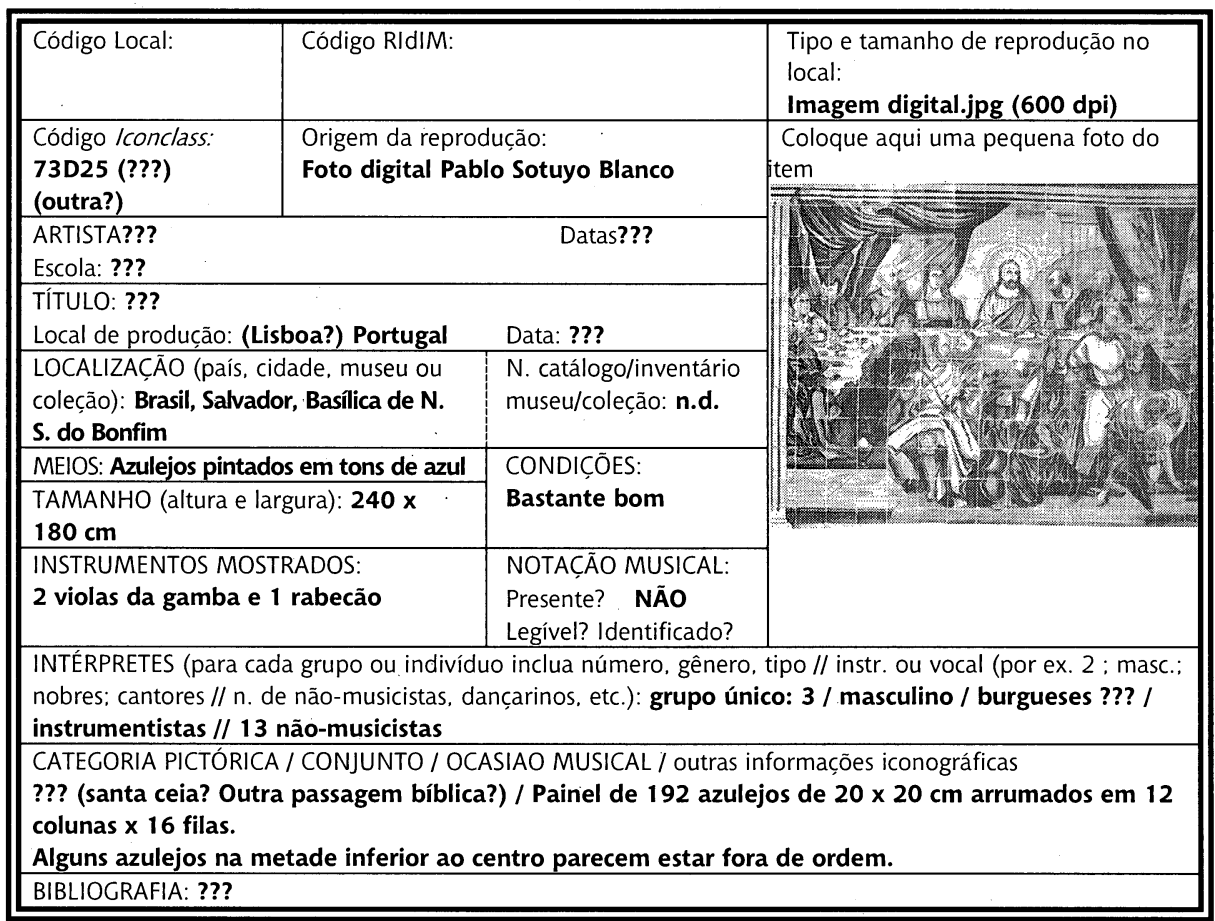

Para responder a tais questões, se requer naturalmente um conhecimento mais profundo do contexto em que a obra está localizada, do seu histórico, do tema bíblico representado e dos protagonistas envolvidos, como artistas, vendedores etc. Na busca de tais informações, começaremos com o estudo do contexto em que se localiza este painel, isto é, o conjunto dos painéis historiados de azulejos da Basílica de N. S. do Bonfim.

2 No verso desta ficha dispõe-se de espaço para incluir informação sobre outra documentação pertinente. A primeira versão desta ficha catalográfica foi definida em fevereiro de 1972 (Cf. BROOK et al., 1972). A versão que aqui apresentamos é uma versão em português adaptada a partir da ficha anexa ao relatório do RIdIM-Canadá de Maria Calderisi encaminhado ao Comitê Organizador do Congresso da International Association of Music Libraries and Documentation Centers (IAML) de 1975. Atualmente esta ficha é utilizada apenas como descrição primária quando não se tem acesso à internet para realizar a catalogação definitiva e apropriada segundo as normas e padrões mais atualizados do RIdIM (que novamente incluem o código de classificação do /conclass (Cf. Iconclass Libertas Browser. Disponível em: <http://www.iconclass.nl/>). 


\section{Os azulejos da Basílica de Nosso Senhor do Bonfim}

Na tentativa de elucidar qual o momento dos evangelhos que a cena do painel aqui estudado representa, foi observado o conjunto dos 28 painéis a fim de tentar encontrar alguma lógica ou nível de relação que ajudasse neste sentido. Segundo se expõe no Quadro 2, exceção feita do painel que representa Moisés recebendo as Tábuas da Lei (oriunda do Velho Testamento), a seqüência dos painéis de azulejos alterna cenas da vida de Jesus (oriundas, portanto, do Novo Testamento) com a representação de personagens importantes na história da Igreja Católica (como santos, papas etc.), incluindo a representação dos quatro evangelistas (acompanhados com os animais que os simbolizam). Temos assim que, dos 28 painéis, apenas 8 na galeria esquerda e 10 na galeria direita representam cenas da vida de Jesus descritas nos Evangelhos contidos no Novo Testamento.

A seqüência linear dos painéis a partir da entrada lateral esquerda não segue a seqüência cronológica dos eventos narrados nos Evangelhos, pois enquanto na parede externa da galeria esquerda (a dos painéis

74 numerados de 1 a 7 , no Quadro 2) começa com João batizando Jesus e termina com João sendo decapitado, a parede interna (a dos painéis numerados de 8 a 14) continua com o nascimento de João Batista para, depois de dois painéis relativos à vida adulta de Jesus (um dos quais é o que aqui nos ocupa), apresentar a cena do menino Jesus na manjedoura. 
Quadro 2 Esquema da distribuição dos painéis de azulejos da Basílica de N. S. do Bonfim

\begin{tabular}{|c|c|c|c|c|c|c|c|c|c|c|c|c|}
\hline \multicolumn{11}{|c|}{ Localização dos painéis } & \multicolumn{2}{|c|}{ Descriçāo possível } \\
\hline & 1 & \multicolumn{2}{|c|}{ Portal } & 2 & 3 & 4 & 5, & 6 & 7 & \multirow{3}{*}{ Sacristia } & 1 - João batiza Jesus & $\begin{array}{l}15 \text { - Sermão da } \\
\text { montanha }\end{array}$ \\
\hline & & \multicolumn{8}{|c|}{ Galeria esquerda } & & $\begin{array}{l}2 \text { - Moisés recebe } \\
\text { tábuas }\end{array}$ & 16 - Fuga ao Egito \\
\hline & 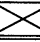 & pta. & 14 & 13 & 12 & 11 & 10 & 9 & 8 & & 3 - São Marcos (leão) & 17 - Jesus e as crianças \\
\hline \multirow{4}{*}{ 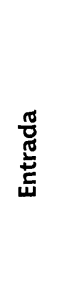 } & \multirow{4}{*}{\multicolumn{9}{|c|}{ Nave central da Basílica de N.S. do Bonfim }} & \multirow{4}{*}{ Altar } & 4 - Santo ??? Papa??? & 18 - Anunciação \\
\hline & & & & & & & & & & & 5 - São João (águia) & $\begin{array}{l}19 \text { - Multiplicação dos } \\
\text { pães }\end{array}$ \\
\hline & & & & & & & & & & & $\begin{array}{l}6 \text { - São Mateus } \\
\text { (anjo) }\end{array}$ & $\begin{array}{l}20 \text { - Maria lava pés de } \\
\text { J.C. }\end{array}$ \\
\hline & & & & & & & & & & & $\begin{array}{l}7 \text { - João Batista } \\
\text { executado }\end{array}$ & 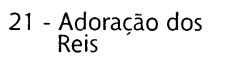 \\
\hline \multirow{3}{*}{ 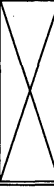 } & 15 & pta. & 16 & 17 & 18 & 19 & 20 & 21 & 22 & \multirow{3}{*}{ Ex-votos } & 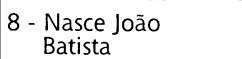 & $\begin{array}{l}22 \text { - Morte das } \\
\text { crianças }\end{array}$ \\
\hline & \multicolumn{9}{|c|}{ Galeria direita } & & 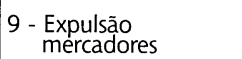 & 23 - Jesus pregando \\
\hline & 23 & Por & & 24 & & 25 & 26 & 27 & 28 & & 10 - Ceia/festa ??? & 24 - São Lucas (boi) \\
\hline \multirow{4}{*}{\multicolumn{11}{|c|}{ NOTA: o painel aqui estudado é o de número 10 . }} & 11 - Na manjedoura & 25 - São Bento \\
\hline & & & & & & & & & & & $\begin{array}{c}12 \text { - São Pedro } \\
\text { (chave) }\end{array}$ & 26 - FALTANTE \\
\hline & & & & & & & & & & & 13 - Maria e Isabel & 27 - São Paulo ??? \\
\hline & & & & & & & & & & & $\begin{array}{c}14 \text { - J.C. o bom } \\
\text { pastor??? }\end{array}$ & $\begin{array}{l}28 \text { - Lava-pés última } \\
\text { ceia }\end{array}$ \\
\hline
\end{tabular}

Tentando identificar a cena representada a partir da proximidade física entre painéis e a possível relação entre eles, a observação dos painéis em torno do de número 10 (Jesus criança na manjedoura e adulto no templo expulsando os mercadores) com os da parede oposta (a representação de um Santo ou um Papa - ainda não identificado - e a dos evangelistas João e Mateus) poderia sugerir uma possível relação entre as cenas representadas nos painéis e os eventos descritos por esses evangelistas. Nesse sentido uma busca na versão Católica da Bíblia online $e^{3}$ por palavras-chave tais como "refeição", "almoço", “ceia", “jantar", "festa”, "batismo", “aniversário", "casamento", "banquete" e "boda" (claramente vinculadas à aparência da cena representada no painel), deu os seguintes resultados, conforme Tabela que segue:

${ }^{3}$ Cf. Bíblia Católica Online, disponível em: <http://www.bibliacatolica.com.br>. 
Tabela Resultados da ocorrência de palavras-chave nos Evangelhos

\begin{tabular}{|c|c|c|c|c|}
\hline Palavra & Evangelista & Ocorrências & Versículos & Passagens bíblicas \\
\hline Refeição & Mateus & 1 & $26: 26$ & Santa Ceia \\
\hline & Marcos & 2 & $14: 12: 14: 22$ & Preparação da Páscoa: Santa Ceia \\
\hline & Lucas & 1 & $14: 1$ & Aos fariseus acerca dos sábados \\
\hline & João & 0 & - & - \\
\hline Almoço(a) & Mateus & 0 & - & - \\
\hline & Marcos & 0 & - & - \\
\hline & Lucas & 0 & - & - \\
\hline & João & 0 & - & - \\
\hline Ceia & Mateus & 2 & $26: 17: 26: 21$ & Preparação da Páscoa; Santa Ceia \\
\hline & Marcos & 0 & - & - \\
\hline & Lucas & 7 & $\begin{array}{l}14: 12-13 ; 14: 16-17 \\
14: 24 ; 17: 8 ; 22: 8\end{array}$ & $\begin{array}{l}\text { Lições sobre humildade: Preparação da } \\
\text { Páscoa: }\end{array}$ \\
\hline & João & 3 & $12: 2: 13: 2: 21: 20$ & $\begin{array}{l}\text { Ceia com Lázaro com Marta; Santa Ceia; } \\
3^{\text {a }} \text { aparição de Jesus aos discipulos }\end{array}$ \\
\hline Jantar & Mateus & 0 & - & - \\
\hline & Marcos & 0 & - & - \\
\hline & Lucas & 1 & $11: 37$ & Ceia com fariseus \\
\hline & João & 0 & - & - \\
\hline Festa(im) & Mateus & 5 & $\begin{array}{l}6: 16 ; 14: 6: 22: 8 \\
26: 5: \\
27: 15\end{array}$ & $\begin{array}{l}\text { Ensinamento do Pai Nosso; Salomé } \\
\text { dança; Parábola das bodas nos Céus; os } \\
\text { Sacerdotes com Caifás; Jesus com Pilatos; }\end{array}$ \\
\hline & Marcos & 4 & $14: 1-2 ; 14: 12 ; 15: 6$ & $\begin{array}{l}\text { Preparação da Páscoa: os Sacerdotes com } \\
\text { Caifás: Jesus com Pilatos; }\end{array}$ \\
\hline & Lucas & 9 & $\begin{array}{l}2: 41-43: 12: 36 \\
15: 23-24 \mathrm{e} 32 ; 22: 1 \\
23: 17\end{array}$ & $\begin{array}{l}\text { Jesus com } 12 \text { anos em Jerusalém; } \\
\text { Sermão sobre a vigília; Parábola do filho } \\
\text { pródigo: Preparação da Páscoa; Jesus } \\
\text { com Pilatos }\end{array}$ \\
\hline & João & 15 & $\begin{array}{l}\text { 2:23: 4:45: } 5: 1: 6: 4 \\
\text { 7:2e8e } 10-11 \mathrm{e} 14 \mathrm{e} 37 \\
10: 22 ; 11: 56: \\
12: 12 \mathrm{e} 20 ; 13: 1 \mathrm{e} 29\end{array}$ & $\begin{array}{l}\text { Referências à Páscoa, à festa dos } \\
\text { Tabernáculos, à da Dedicação; Santa } \\
\text { Ceia }\end{array}$ \\
\hline Batismo & Mateus & 2 & $3: 7: 21: 25$ & Jesus questiona os fariseus \\
\hline & Marcos & 4 & $\begin{array}{l}1: 4: 10: 38 ; 10: 39 \\
11: 30\end{array}$ & $\begin{array}{l}\text { João Batista: Tiago e João pedem para } \\
\text { juntar-se à gloria de Jesus; Jesus } \\
\text { questiona os Sacerdotes }\end{array}$ \\
\hline & Lucas & 5 & $\begin{array}{l}3: 3: 7: 29-30: 12: 50 \\
20: 4\end{array}$ & $\begin{array}{l}\text { João Batista; Jesus questiona os } \\
\text { Sacerdotes }\end{array}$ \\
\hline & João & 0 & - & - \\
\hline Aniversário & Mateus & 1 & $14: 6$ & Salomé dança \\
\hline & Marcos & 0 & - & - \\
\hline & Lucas & 0 & - & - \\
\hline & João & 0 & - & - \\
\hline Casamento & Mateus & 1 & $24: 38$ & Sobre a volta do Filho do Homem \\
\hline & Marcos & 0 & - & - \\
\hline & Lucas & 6 & $20: 34$ & Sobre a volta do Filho do Homem \\
\hline & João & 0 & - & - \\
\hline Banquete & Mateus & 3 & $22: 4 \mathrm{e} 10: 23: 6$ & Parábola das bodas nos Céus \\
\hline & Marcos & 2 & $6: 21 ; 12: 39$ & Salomé dança; sobre humildade \\
\hline & Lucas & 3 & $5: 19: 16: 19 ; 20: 46$ & Liçōes sobre humildade \\
\hline & João & 0 & - & - \\
\hline Boda(s) & Mateus & 10 & 22:2e4e9; $25: 10$ & Parábola das bodas nos Céus \\
\hline & Marcos & 0 & - & - \\
\hline & Lucas & 1 & $14: 8$ & Liçōes sobre humildade \\
\hline & João & 2 & $2: 1$ & Bodas de Caná \\
\hline
\end{tabular}


Como resulta da Tabela 1, a maior ocorrência das passagens bíblicas nos Evangelhos de Mateus e João (sendo estes os dois painéis de azulejos que ficam mais próximos da parede oposta) corresponde à Santa Ceia e à Parábola das bodas nos Céus (em negrito na Tabela 1) - esta última majoritariamente no Evangelho de Mateus. O comportamento visivelmente relaxado dos comensais (incluindo o que está com uma taça na mão e outro abaixado, trafegando alguma bebida de um jarro a outro), além da presença dos músicos, levaria a desconsiderar de vez a Santa Ceia como tema do painel. Por outro lado, há um detalhe que, embora aparentemente insignificante e "estatisticamente" sem valor, na Tabela 1, parece ganhar força pela sua sugestiva clareza dialética e apologética entre os evangelistas João e Mateus.

Segundo a numeração atribuída aos painéis no Quadro 2, tomados frontalmente, isto é, o \#5 com o \#10 e o \#6 com o \#9, poder-se-ia interpretar que a passagem representada no painel \#10 teria sido especialmente citada por João Evangelista (painel \#5). Enquanto isso, a passagem do painel \#9 (Jesus expulsando os mercadores do templo) é um evento que, por sua vez, teria sido especialmente referido no Evangelho de Mateus. Uma nova busca na bíblia on-line pela frase-chave "no templo" mostra que a referida passagem da expulsão dos mercadores foi incluída em todos os Evangelhos, incluindo o de João. Assim, não havendo uma relação de exclusividade entre dita passagem e o Evangelho de Mateus, olhamos novamente a Tabela 1 em busca de relações de exclusividade ou exclusão de passagens com relação ao Evangelho de João. Nesse sentido a única passagem referida exclusivamente por João é a das Bodas de Caná.

Será essa relação de exclusividade entre as Bodas de Caná e o Evangelho de João a chave para identificar a cena representada no painel de número 10 , colocado defronte ao painel que representa João Evangelista?

\section{Desvelando o mistério: das violas da gamba às Bodas de Caná}

Segundo Carlos Ott, os 28 "azulejos-tapetes" que decoram os corredores laterais da Basílica, 
são de qualidade inferior, para não dizer que são destituídos de qualquer valor artístico, pois não foi artista e sim apenas artífice. Aí temos um dos casos de regresso da pintura de faianças portuguesas, num tempo em que havia Escolas de Belas Artes por toda a parte. E, no entanto, encarregou-se de uma encomenda volumosa dessas, destinada a um Santuário de fama mundial, um pintor que mal sabia desenhar. Para o povo, estas histórias bíblicas sempre possuem seu valor. [...] Se a responsabilidade dessa aberração coube aos Mesários que não pediram informações minuciosas, ou ao informante, que os enganou, não se pode verificar. A verdade, porém, é que se jogaram fora $1.611 \$ 690$ que se gastaram com estes azulejos e que vieram, em 1855, conforme a fatura de B. M. de Oliveira Borges. Ao pintor dos azulejos, Tomáz do Carmo, pagaram $200 \$ 000$ de gratificação pelo desempenho dos quadros que fez ([nota] 193 [e 194]). (OTT, 1979: 102-105). ${ }^{4}$

Mesmo considerando a baixa qualidade artística dos azulejos da Basílica de N. S. do Bonfim pintados por Thomas José do Carmo (de quem até agora não foi possível localizar nenhuma outra informação biográfica além das acima mencionadas por Ott), o fato de apresentarem um trio de violas da gamba, no primeiro plano de uma das cenas bíblicas pintadas nos azulejos, já configura assunto de interesse ao projeto RIdIM-Brasil, segundo mencionamos no inicio deste trabalho.

Tendo sido pintados em Lisboa a meados do século XIX, o formato e 78 design dos instrumentos, assim como a forma de execução observada, levam

${ }^{4}$ [nota] " 193 - no dia 24 de dezembro de 1855, somos informados que a Irmandade do Sr. do Bomfim pagou $1.611 \$ 690$ a Joaquim Marinho e Cia, de azulejos para a Capella do Bomfim, distribuindo-se da seguinte maneira: 1854 Novembro 11 - a Joaquim Pereira Marinho e Companhia deve - Importe de 28 quadros históricos compostos de 5.060 azulejos, vindos de Lisboa, conforme a factura da B. M. de Oliveira Borges sobre

$677 \$ 945$

Cambio de $100 \%$ $677 \$ 945$

Frete de Brigue Intrépido

$1.355 \$ 890$

$55 \$ 800$

1855 Abril 2 - Dinheiro a Thomas José do Carmo, gratificação pelo

desempenho dos quadros que fez para o Senhor do Bomfim.

$200 \$ 000$

Cambio de $100 \%$

(AIB [Arquivo da Igreja do Bonfim], Recibos 1855 - 1856, n 57)", (apud Carlos Ott p.164).

[nota] "194 - Aos 31 de julho de 1855, a dita Irmandade pagou $270 \$ 000$ ao Mestre Pedreiro Guardiano Pinheiro do Sacramento 'de asentar [sic] os azulejos na parede dos corredores com reboque de novos' (Arquivo da Igreja do Bonfim, Recibos $1855-1856, \mathrm{n}^{\circ}$ 46)" (apud OTT, 1979, p. 164). 
necessariamente a uma revisão da bibliografia relativa aos aspectos organológicos e performáticos das violas da gamba, tidas tradicionalmente como instrumentos renascentistas e barrocos, com forte tradição na França e na Itália.

$\mathrm{Na}$ descrição destes instrumentos fornecida por Luis Henrique (1994) incluída entre "Outros cordofones friccionados" subseção "Viola da Gamba" o referido autor os descreve como:

Instrumento de corda friccionada, construído em diversos tamanhos, que apresenta diferenças notórias em relação aos instrumentos da família do violino. A diferença entre estas duas famílias de instrumentos está resumida na tabela seguinte:

Família da Viola

- 6 cordas

$[\ldots]$

- Braço mais largo

- Escala com trastos

- Cravelhame esculpido em forma de cabeça

- Ângulo acentuado entre a caixa e o braço

\section{- Aberturas em $c c$}

[...]

O instrumentista pega no arco com a palma da mão virada para a frente, ao contrário do que acontece com o violino. O instrumento é mantido verticalmente, entre os joelhos, mesmo que se trate dos instrumentos mais pequenos.

[...]

Não se conhece ao certo a origem das violas da gamba, mas há factos que levam a supor que os instrumentos de corda friccionada tenham resultado da aplicação de um arco aos instrumentos de corda beliscada já existentes. Além disso, as violas apresentam vários pontos de contacto com os cordofones beliscados da Renascença [...]

No quadro intitulado As Bodas de Caná (ver fig. 6.4) de Veronese vêse um dos músicos pegando na viola na posição própria da guitarra, mas friccionando as cordas com um arco. Desta posição ter-se-ia naturalmente passado a apoiar o instrumento verticalmente, o que se torna muito mais prático e cômodo.

A viola da gamba surge no fim da Idade Média, atingindo o seu apogeu no séc. XVIII.

No inicio do séc. XVI, as violas da gamba eram conhecidas entre outras, pela designação viole da tasti (viola com trastos). (Henrique, 1994, p. 122).

Quanta não seria a surpresa do pesquisador que, ao observar a figura com a qual Henrique procurou ilustrar a forma de pegar na viola na posição 
própria da "guitarra" (o nosso violão), verificasse que o painel de azulejos fixado na Igreja do Bonfim (e cujo conjunto foi tão criticado por Ott) é uma recomposição reduzida do famoso quadro que Paolo Caliari, o "Veronese" (Verona, ca. 1528 - Veneza, 19-04-1588), pintor maneirista da Renascença italiana, pintara para o refeitório dos beneditinos na ilha de San Giorgio Maggiore, em Veneza, representando o episódio bíblico das Bodas de Caná (Fig. 4) tendo adaptado uma tela de $6,77 \times 9,94 \mathrm{~m}$. à sala criada por Palladio. ${ }^{5}$

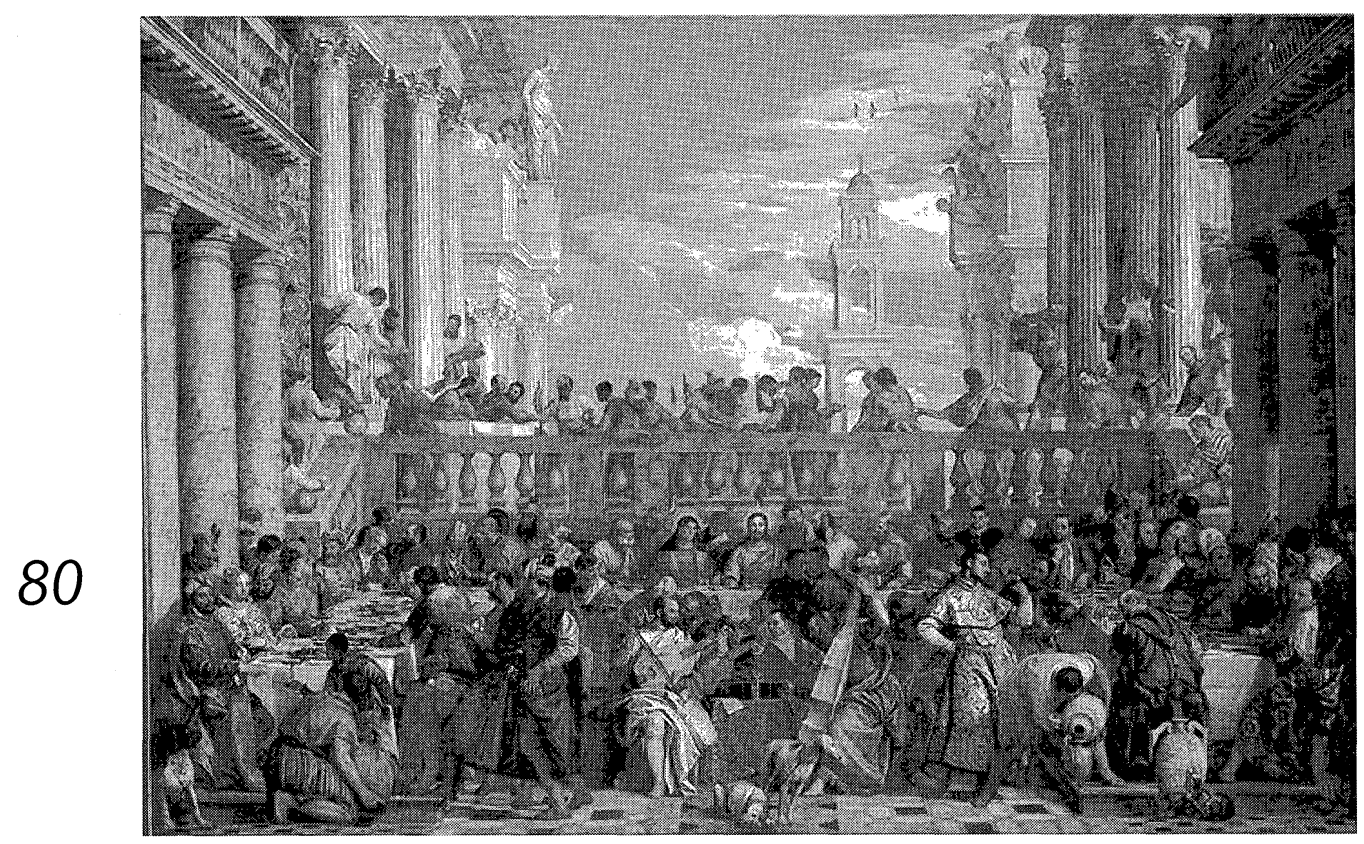

Figura 4 As bodas de Caná - óleo sobre tela de Veronese (1563)

5 Foi em 1563 que os venezianos assistiram à conjunção criadora desses dois gênios: Palladio e Veronese. Porém, no final do século XVIII, o general Bonaparte invadiu a Itália e, como botim, levou obras de arte para o Louvre, museu universal que então se formava em Paris, dentre as quais se contava a tela que nos ocupa neste trabalho. 


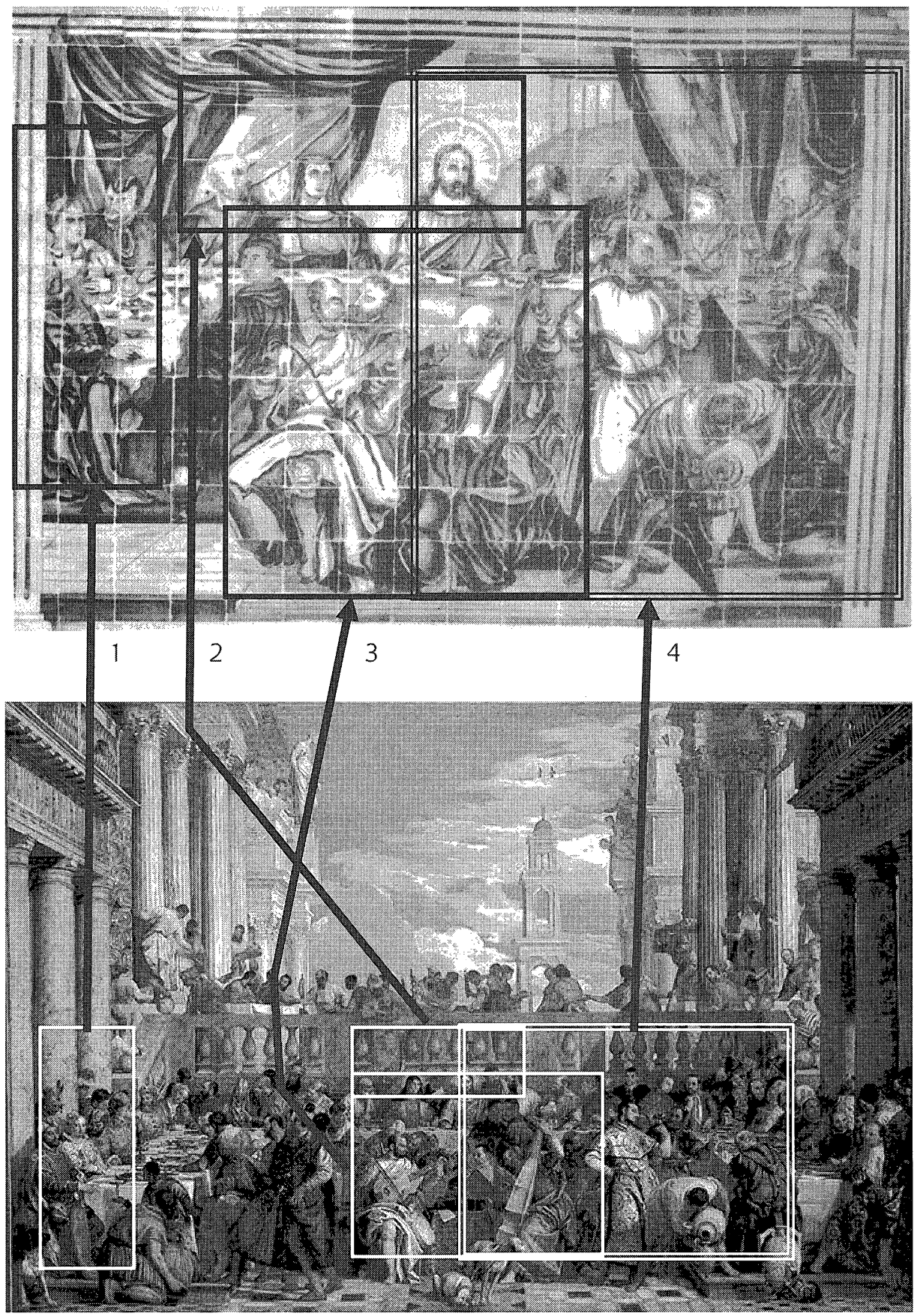

Figura 5 Fragmentos da tela de Veronese usados na re-composição de Tomáz José do Carmo 
Na Figura 5 mostra-se a re-composição simplificada (eliminando e relocando personagens) realizada em Lisboa por Thomáz José do Carmo, baseada em quatro fragmentos da tela de Veronese (de 1 a 4 , na Fig. 5). Indo um pouco além na análise comparada entre ambas as representações dás Bodas de Caná, as Figuras 6 a 9 mostram com maior clareza as mudanças para o painel de azulejos, indicando em cada caso o número de personagens eliminadas assim como das relocadas, geralmente diminuindo a distância entre as mesmas.
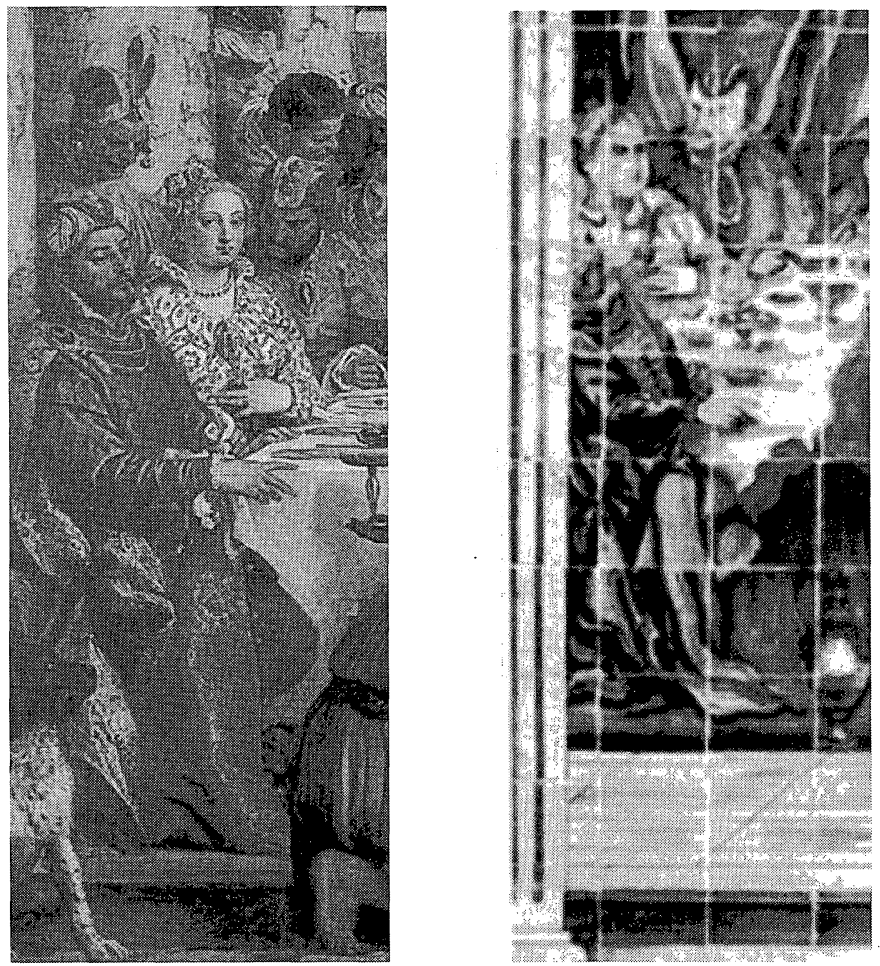

Figura 6 Simplificação do fragmento 1: eliminação de quatro personagens 

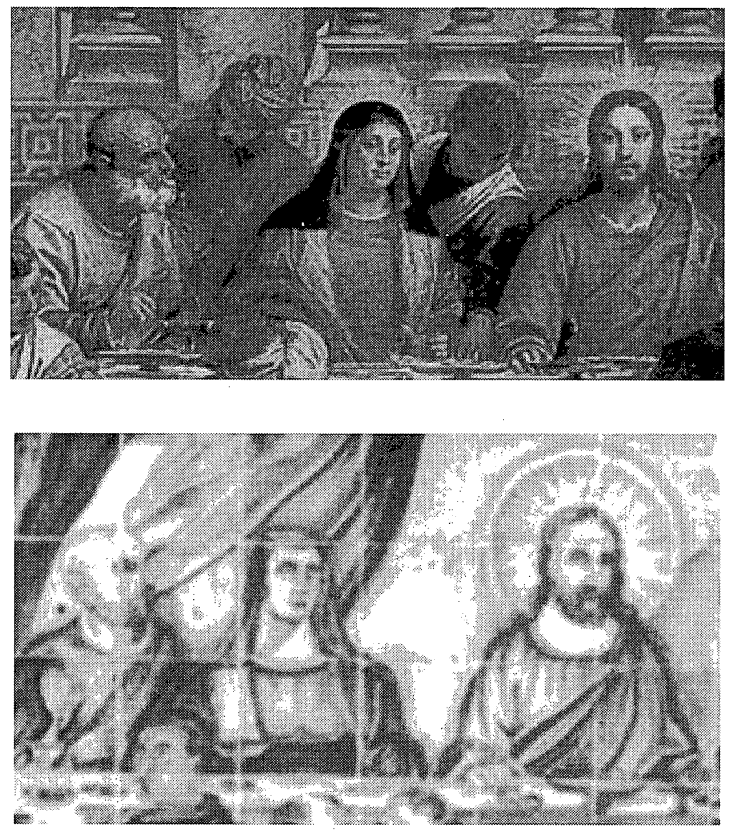

Figura 7 Simplificação do fragmento 2: eliminação e re-locação de três personagens
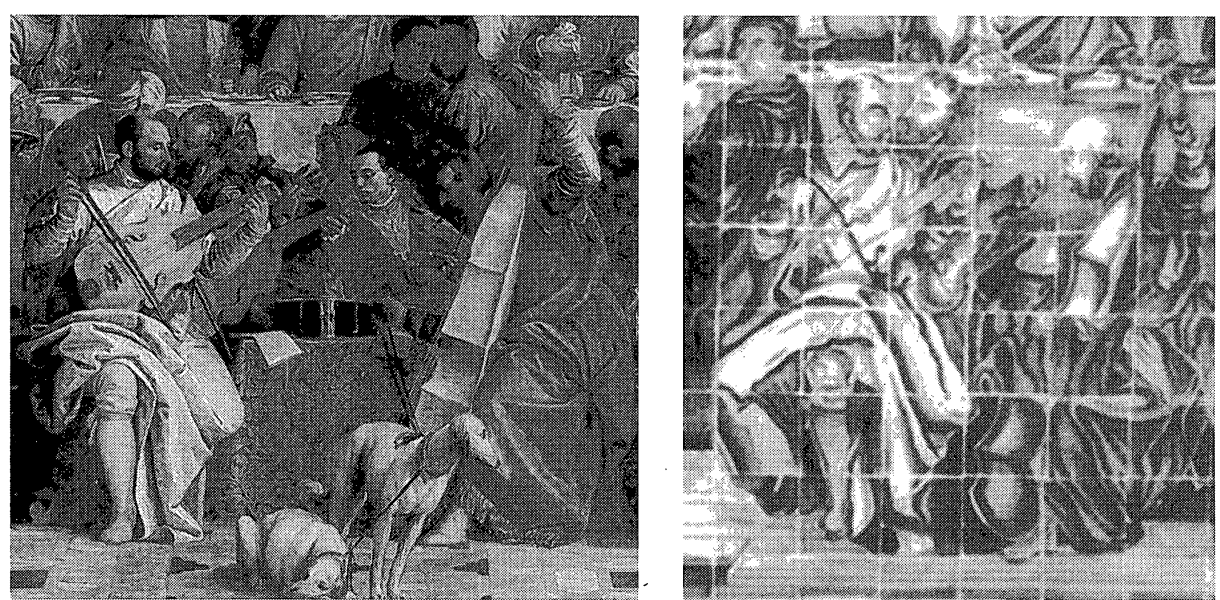

Figura 8 Simplificação do fragmento 3: eliminação de seis e re-locação de quatro personagens 

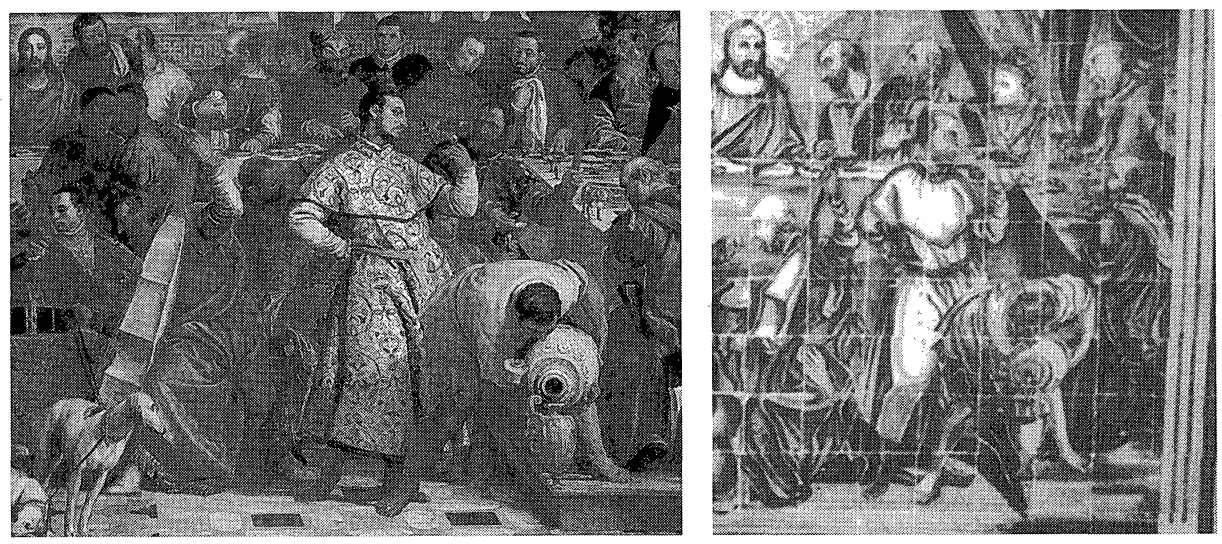

Figura 9 Simplificação do fragmento 4: eliminação de dezoito e re-locação de nove personagens

Embora as aberturas das violas da gamba pintadas por Veronese não possuam a forma de $c$ descrita por Henrique e sim de $f$ (e aqui entendida como licença pictórica), os outros detalhes (número de cordas, cravelhame esculpido, trastos, forma de pegar no arco), conferem aos instrumentos as características esperadas nas violas da gamba.

Confirmada assim a temática bíblica do painel e eliminada toda possível 84 originalidade iconográfica musical portuguesa, no intuito de compreender melhor as iconografias musicais aqui relacionadas, só resta avançar em dois sentidos possíveis: a) análise da representação iconográfica musical no contexto da Veneza renascentista; e b) análise da representação iconográfica musical no contexto do imaginário português relativo à Igreja do Bonfim, à Bahia e, porque não, ao Brasil de meados do século XIX.

Iniciando pela análise iconográfica no contexto da Veneza renascentista, segundo Mendes:

Entre as cerca de 150 pessoas representadas nas "Bodas de Caná", Veronese terá retratado numerosas personalidades célebres do seu século, como Francisco I (morreu em 1547).

[...] Em 1771, o escritor de arte Zanetti sustentava uma hipótese igualmente pouco fundamentada, mas bem mais sedutora: a pequena orquestra [sic] ao centro do quadro reagruparia os pintores mais conhecidos 
de Veneza. "O tocador de rabecão não pode ser outro senão Ticiano" escreve Zanetti a propósito do homem de vermelho sentado à direita. "Paolo representou-se a si próprio sob os traços do violoncelista [sic] vestido de branco". Quanto ao seu vizinho, "é razoável imaginar tratar-se de Jacopo Tintoretto". Se isto for verdade - e comparações com outros retratos parecem corroborar tal hipótese - significa que os três mestres incontestados da pintura veneziana do século XVI, os três grandes coloristas, se encontraram aqui para fazer música.

Haviam sido honrados com importantes encomendas do Estado e trabalhavam afincadamente a decorar, com pinturas, as igrejas de Veneza e os edifícios do governo. Paolo Caliari era o mais novo dos três [...]. Conheceu os seus primeiros sucessos em Veneza com a decoração da biblioteca de S. Marcos. Em 1557 terá recebido, como recompensa, um colar de ouro das mãos de Ticiano, então homem de muita idade. O Tintoretto (1518-1594) era um excêntrico e nunca teve em vida o reconhecimento público igual ao de Ticiano (cerca de 1477-1576) que foi elevado ao grau de cavaleiro e adorado como um deus, como um divino. É provável que os pintores se encontrassem em casa de Ticiano que possuía um órgão oferecido por um fabricante de órgãos em troca de um retrato.

No século XVI fazia-se música em todas as casas de Veneza. Em 1506, Duerer que estava de visita, escrevia ter ouvido violinistas cuja música era tão divina que os próprios músicos se comoviam até às lágrimas. É muito possível que a música tocada no banquete de Veronese tivesse sido composta por Andrea Gabrieli, organista de S. Marcos e o maior compositor desse tempo. As melodias de Gabrieli eram ouvidas nos salōes, nos teatros e nas praças públicas e as pesquisas que fazia no domínio da harmonia fascinavam também pintores e escultores. "Se o equilíbrio das vozes é harmonioso para o ouvido", explicava em 1525 o monge letrado Francesco Giorgi, "as proporções físicas são harmoniosas para o olhar. Tais harmonias proporcionam o maior dos prazeres sem que ninguém se aperceba porque razão, excepto aquele que conhece a causalidade de todas as coisas.". Todos os compositores, arquitectos e pintores procuravam essa "causalidade" e a harmonia perfeita dos tons, da proporção e da cor. (Mendes, 2000).

Embora a "pequena orquestra" referida por Mendes (Fig. 10) não seja mais do que um conjunto de seis músicos ${ }^{6}$ e o "violoncelo" que afirma ser executado por Veronese seja uma viola da gamba, se observa que a simplificação operada por Thomas José do Carmo (Fig. 8) converteu o sexteto num trio. Além, do duo de violas da gamba e o rabecão, Veronese incluiu um trompete (à esquerda, atrás das violas da gamba), uma possível gaita de foles (ao centro, atrás das violas da gamba) e uma rabeca (entre o rabecão e a gaita de foles), assim

\footnotetext{
${ }^{6} \mathrm{~A}$ orquestra como orgânico instrumental surgiu no inicio do período Barroco.
} 
como uma mesa, no meio dos músicos, onde se apóiam as partes instrumentais cuja notação não é identificável nem legível junto ao um relógio de areia. Ainda constam outras duas pessoas que, aparentemente integradas no conjunto, não foi possível identificar quais instrumentos eles estariam tocando.

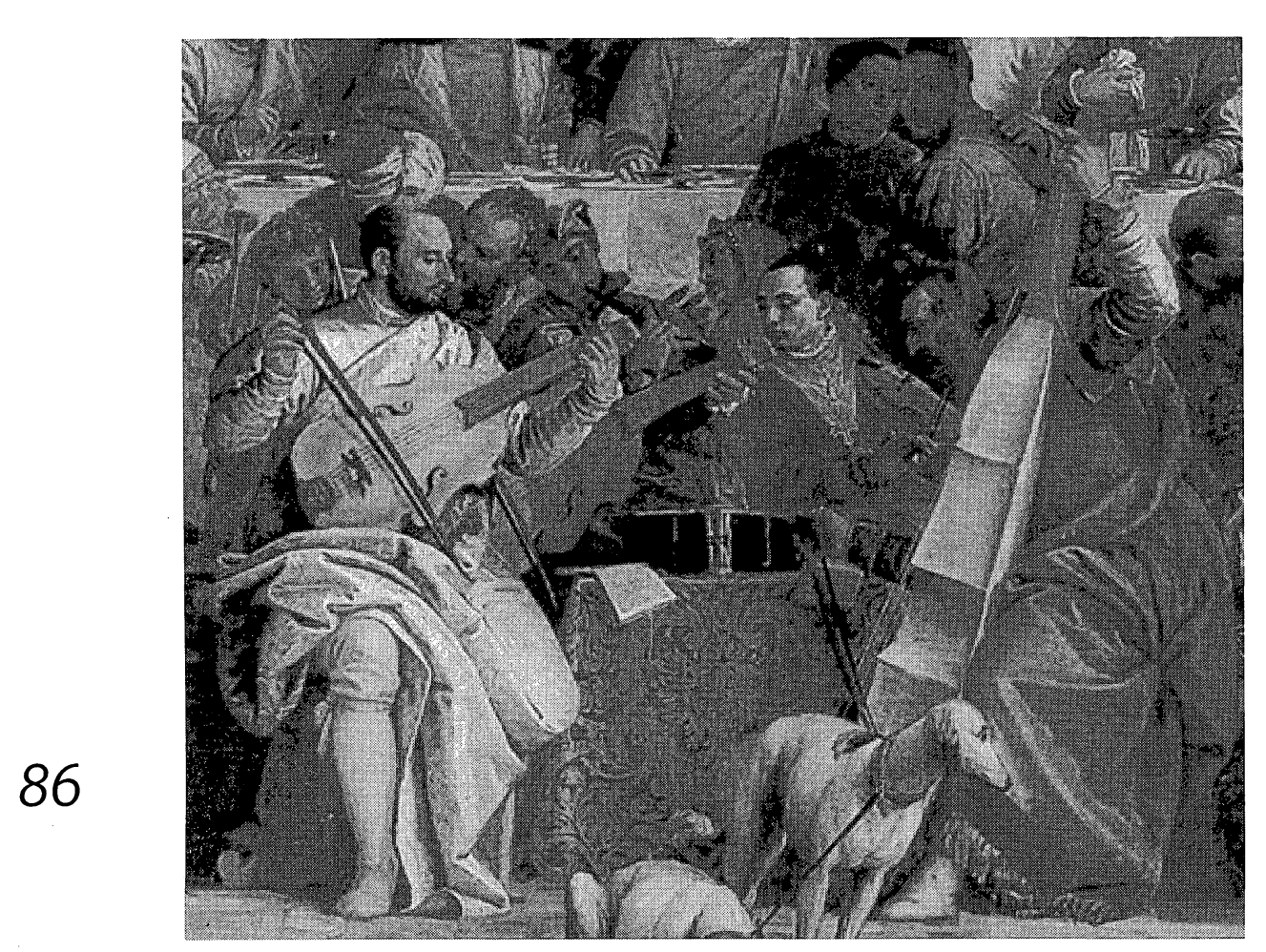

Figura 10 As bodas de Caná - óleo sobre tela de Veronese (1563) - detalhe do conjunto musical

Continuando com a análise da representação iconográfica musical no contexto do imaginário português realizado para a Basílica de N. S. do Bonfim pelo português Thomas José do Carmo em meados do século XIX, pode-se observar que a recomposição iconográfica do painel aqui estudado poderia exemplificar a decadência em que Portugal mergulhou naquele momento.

Embora a apropriação de modelos imagéticos preexistentes tenha uma longa tradição no mundo cristão (Cf. Eusébio, 2005), a azulejaria em Portugal data de finais do século XV. Desde então até o terceiro quartel do século XVIII a 
indústria dos azulejos em Portugal foi desenvolvendo as suas características mais marcantes (sobretudo os painéis em azul e branco - influência recebida da Holanda), através dos trabalhos de mestres tais como Gabriel del Barco e Antonio de Oliveira Bernardes, fazendo-Ihe merecer a sua grande popularidade tanto em Portugal quanto no Brasil. Mas na virada do século XVIII para o XIX, segundo analisa Tânia Tribe, os painéis historiados de azulejos pintados começaram a perder qualidade técnica e artística, em parte pelo desinteresse que a crescente mecanização e novas formas de produção, traziam à sociedade.

Ambiguamente colocados entre a arte e o artesanato, os azulejos pintados refletiram os gostos, ideais e valores da elite, que incluíam as principais ordens religiosas, irmandades de leigos como as Misericórdias e ordens terceiras, membros da aristocracia e mercadores abastados.

[...] Durante o período, no entanto, mudanças na forma foram mais visíveis do que no conteúdo. A natureza basicamente religiosa e alegórica do discurso pintado nos painéis de azulejos permaneceu notadamente constante, a despeito da abertura de setores da sociedade portuguesa às novas idéias de experimentação científica, mecanização e comercio. Quando tais idéias foram finalmente estabelecidas, a pintura de azulejos começou a declinar como importante forma artística. (Tribe. 2008. Tradução nossa). ${ }^{7}$

Esse declínio de final do século XVIII comentado por Tânia Tribe se adentrou bastante no século XIX, explicando (pelo menos parcialmente) não apenas a escolha do pintor Thomas José do Carmo de recompor e reduzir a obra prima de Veronese, mas também a sua falta de qualidade técnica, como já foi mencionado por Ott.

\footnotetext{
7 Original: "Ambiguously poised between art and craft, tile paintings reflected the tastes, ideals and values of the elite, which included the major religious orders, lay brotherhoods like the Misericordias and third orders, members of the aristocracy, and wealthy merchants. / [...] Throughout the period, however, changes in form were more noticeable than changes in content. The basically religious and allegorical nature of the discourse painted in tile panels remained remarkably constant, despite the opening up of sections of Portuguese society to new ideas of scientific experimentation, mechanization and commerce. When such ideas were finally implemented, tile painting had begun to decline as an important art form."
} 


\section{Considerações finais}

Muitas são as armadilhas que o processo de catalogação de iconografia musical pode colocar na frente do pesquisador como ficou exemplificado neste texto. Depois de realizada a pesquisa aqui apresentada, a versão final da Ficha de catalogação deste item pelo RIdIM-Brasil ficou segundo aparece no Quadro 3.

Como vimos, para tal, foi necessário, além da revisão bibliográfica relativa ao estado do conhecimento em torno da Basílica de N. S. do Bonfim, da azulejaria portuguesa, de passagens do Novo Testamento, de organologia e de pintura renascentista (dentre outros tópicos aqui levantados), depararmonos com as transformações que o pintor Thomas José do Carmo efetuou da pintura em policromia de Veronese, para produzir o painel de azulejos que aqui nos ocupou. No estudo dessas mudanças se destacaram a troca do espaço aberto ao céu, tão possante na pintura de Veronese, em uma sala aparentemente fechada; a redução para 18 das 150 figuras iniciais; assim como das simplificações (por eliminação e re-locação de personagens) 88 incluindo parte do conjunto de músicos central (alem da desordem na colocação de alguns dos azulejos). Tudo isso de forma tão aparentemente precária que nos obriga a concordar com Ott acerca da baixa qualidade estética do trabalho técnico do pintor. Ainda o estudo das origens iconográficas dos painéis restantes, isto é, relativas aos modelos pictóricos utilizados por Thomas José do Carmo nos outros painéis da Basílica do Nosso Senhor do Bonfim, ficará para o futuro próximo.

Finalmente, se para Mendes existe uma grande possibilidade de que a música sendo executada na pintura de Veronese seja de Andrea Gabrielli, na então Igreja de Nosso Senhor do Bonfim em meados do século XIX, os músicos não podiam estar tocando outra coisa que não fosse Mussurunga, Barbosa de Araújo ou João Manoel Dantas, dentre outros. 
EUSÉBIO, Maria de Fátima. 2005. A apropriação cristã da iconografia greco-latina: o tema do Bom Pastor. Máthesis n. 14. p. 9-28. Disponível em: http://z3950.crb.ucp.pt/biblioteca/Mathesis/ Mat14/Mathesis14_9.pdf. Acesso em: 20 jun. 2008.

HENRIQUE, Luis. 1994. Instrumentos Musicais. 2. ed. Lisboa: Fundação Calouste Gulbenkian.

MENDES, Paula. 2000. Os pintores tocam para os convidados, In: As Bodas de Caná. Paolo Caliari (Veronese). Para a cadeira de Informática Aplicada ao Jornalismo. Instituto de Estudos Jornalísticos. Faculdade de Letras. Universidade de Coimbra. Disponível em: <http://www1.ci.uc.pt/iej/alunos/1999-2000/bodas/pagina4.htm>. Acesso em: 15 maio 2008.

OTT, Carlos. 1979. Evolução das artes plásticas nas lgrejas do Bonfim, Boqueirão e Saúde. Salvador: Universidade Federal da Bahia, Centro de Estudos Baianos. p. 102-105.

TRIBE, Tania C. The heroic and the gallant: Tile painting in Portugal and Brazil, 16701780. Ph.D. diss., University of Essex (United Kingdom), 1994. In: Dissertations \& Theses: Full Text. Disponível em: <http://www.proquest.com.proxy.uchicago.edu/>. Acesso em: 5 dez. 2008. 
Anexo I - Descrição dos campos da Ficha de Catalogação do RIdIM (Cf. Brook et al., 1972)

Código local (Local sig/um) - número de referencia usado pela coleção individual.

Código RIdIM (RIdIM sig/um) - código opcional baseado em acordo internacional a ser estabelecido posteriormente.

Iconclass - Número de classificação opcional derivado do Decimal Index of the Art of the Low Countries de H. van de Wall (The hague. 2nd ed., 1971).

Origem da foto - indicar se foto institucional, acrescentando nome completo do fotógrafo, cidade e pais. Indicar endereço quando origem pouco conhecida. Se a reprodução local é uma re-fotografia de um livro ou artigo. indica-lo.

Tipo de reprodução local - indicar o tipo de reprodução de cada obra no documento e disponivel na coleção com uma das seguintes designaçōes:

A - reproduzida em artigo

B - em livro

C - cartão postal ou semelhante

D - diapositiva ou slide

$\mathrm{F}$ - filme positivo

MF - microficha

$\mathrm{N}$ - filme negativo

$\mathrm{PH}$ - fotografia separada

PR - impresso separado, usualmente tomada de publicação efêmera

$X$ - impresso xerográfico (fotocópia) de livro ou artigo

Um $c$ minúsculo depois de quaisquer das categorias anteriores significa que a reprodução é colorida.

Tamanho: Altura x largura em cm.

ARTISTA - Sobrenomes com prefixos separados são ingressados sob o artigo do prefixo ou a contração artigo/preposição. Uma preposição destacada aparece no final do nome. i.e.: Hooch, Pieter de; La Laurencie, Lionel de.

Nomes medievais consistentes de nome e local associado são ingressados pelo nome.

Se o nome real do artista não for conhecido, forneça a designação, monograma etc. pelo qual for conhecido (i.e. Mestre da Glorificação de Nossa Senhora; Mestre E.S.; etc.) e catalogue sob Mestre.

Se o artista for desconhecido, escreva Anon., catalogue pela Escola e data do item. Se mais de um artista estiver envolvido, especialmente no caso de um impresso, forneça todos os nomes dos artistas colaboradores, datas e escolas, seguido da função segundo aparece no impresso: i.e. sculpsit, pinxit, excudit etc.

Quando for o caso, use as palavras: loja, escola, baseado em, antigamente atribuído a, etc. seguindo a entrada por artista/datas/escola/.

Datas - Quando se desconhecem as datas exatas, forneça as datas aproximadas precedidas por ca. Quando as datas aproximadas forem também desconhecidas, forneça o período, i.e. $2^{\mathrm{a}}$ metade do séc. XVI. 
Escola - A escola é determinada por nacionalidade, seguida, se quiser, por dois pontos e uma designação de estilo mais específica: i.e. Francês: surrealismo.

TíTULO - Forneça o título na língua original quando factível, seguido, se possível, da tradução ao inglês entre colchetes.

Nos casos em que a obra é conhecida por mais de um título, forneça primeiro o mais amplamente conhecido, acrescentando depois a(s) outra(s) versão(ões).

Quando não houver um título, crie um que seja suficientemente descritivo e indique-o entre colchetes.

Datas - Forneça as datas específicas do item quando forem conhecidas, ou a melhor estimativa do período.

Local de produção - quando for conhecido.

NOTA: Nos casos em que a obra faz parte de uma unidade maior, acrescente o contexto (i.e. Um dos quatro anjos músicos do altar) depois da entrada de Título/data/local de produção.

LOCAL - País - Abreviatura ISO pode ser utilizada (veja a lista de abreviaturas do RILM),

Cidade - na língua original.

Museu ou coleção - na língua original.

Número de catálogo no museu/na coleção - $O(s)$ número(s) pelo(s) qual(is) o item pode ser localizado no museu ou na coleção. O número de filme do museu também deveria ser incluído, quando disponível.

\section{MEIOS}

1. desenho

2. dourado; patinado (ename)

3. vidro

4 iluminura de manuscrito

5. marquiseria

6. mosaico

7. bordado (needlework)

8. pintura (não especificado)

9. óleo

10. aquarela

11. afresco

14. impresso (não especificado)

15. talha

16. gravura

17. etching

18. litografia

19. fotografia

20.

21. escultura (não especificado)

22. relevo

23. auto-sustentada

24.

12. têmpera

13.

25. tapeçaria

Nos casos em que a obra pertencente a uma categoria normalmente não colorida, for colorida, acrescente $c$.

Acrescente detalhes quando for pertinente; i.e. desenho: caneta e tinta sobre seda; pintura: gouache sobre tela; No caso dos relevos, acrescente bas ou haut.

Tamanho - Altura e largura em $\mathrm{cm}$.

Condições - Restaurado? Partes faltantes, extraviadas etc. 


\section{INSTRUMENTOS MOSTRADOS}

1. Teclado (sem especificação)

2. cravo (clavichord)

3. harpsichord

4. órgão, grande

5. órgão, portativo

6. órgão, positivo

7. pianoforte

8. espineta/virginal

9.

10. corda, friccionada (não especificado)

11. fiddle

12. organistrum

13. rebec

14. trompeta marinha

15. viol

16. violino/viola

17. violoncelo

18. zither, friccionado

19.

20. corda, beliscada (não especificad

21. cittern

22. violão/guitarra

23. harpa

24. alaúde

25. lira/cítara

26. mandora

27. saltério

28. zither

29.

30. sopro (não especificado)

31. aulos/tibia

32. gaita de fole

33. fagote/curtal sopro (cont.)

34. bladder pipe

35. clarinete

36. cornet

37. crumhorn

38. flauta, transversal

39. trompa

40. oboé

41. panpipe

42. pipe e/ou tabor

43. racket

44. flauta doce recorder

45. shawm

46. trombone

47. trompete

48. tuba

49.

50. percussão (não especificado)

51. sino, clapper

52. sino, pellet

53. sino, struck

54. clappers

55. cymbal

56. tambor, barril

57. tambor, cilíndrico

58. tambor, frame

59. tambor, kettle

60. pot, percutido

61. chocalho

62. triângulo

63. xilofone

64.

Acrescente detalhes quando for possível, i.e. arpa com quatro cordas; rabeca sem apoio; etc.

Para instrumentos étnicos, utilize por gentileza a terminologia empregada em Ethnical Musical Instruments (Londres: ICOM, 1970) editado por Jean Jenkins, presidente de um grupo de trabalho do CIMCIM (Comité International des Musées et Collections d'Instruments de Musique) do International Council of Museums (ICOM).

Notação musical - Forneça nome da obra e do compositor quando for possível. 


\section{INSTRUMENTISTAS}
1. Nobreza
9. músico profissional
2. Clero
10. grotesco
3. soldado
11. anjo
4. burguês
12. santo
5. ator
13. animal
6. pastor
14. bobo ou bufão
7. camponês
15.
8. músico de rua

Número de não-instrumentistas - Forneça o número aproximado

\section{CATEGORIA PICTÓRICA}

1. cena de gênero

8. caricatura

2. narrativa

9. desenhado para ...

3. natureza morta

10. alegoria

4. decoração

11. obra didática

5. retrato

12. vinheta

6. retrato grupal

13.

7. estudo vivo

\section{LOCAL}
1. interior
11. edifício civil
2. exterior
12. taverna
3. paraíso
13. ateliê
4. inferno
14. teatro
5. roça
15. jardim
6. sobre ou perto de água
16. galpão
7. vila
17. banho
8. cidade
18. acampamento militar
9. igreja
10. interior doméstico
19. rua ou praça
20.

\section{OCASIÃO PARA A MÚSICA}

1. coroação

2. funeral

3. boda

4. Missa ou ofício

5. caça

6. dança

7. baile

8. feira

9. evento teatral

10. carnaval

11. batalha
12. torneio

13. revista militar

14. aula de música

15. refeição

16. procissão

17. serenata

18. música doméstica

19. concerto

20. ensaio

21. 
Outra informação iconográfica - Acrescente qualquer coisa que for pertinente.

BIBLIOGRAFIA - Listas livros e artigos que contenham discussões ou reproduções do item catalogado. Anote quando possível (a presença de uma ilustração do item é subentendida, exceto quando a expressão no ill. é indicada entre parênteses). Quando o livro ou artigo está disponível na coleção local, um asterisco deveria ser colocado no inicio da citação.

Pablo Sotuyo Blanco: psotuyo@gmail.com

Artigo recebido e aprovado em 15 de maio de 2009 